\title{
HEIDEGGER E O FIM DO MUNDO
}

\section{Alexandre Franco de Sá}

Universidade de Coimbra

A comunicação que aqui pretendemos apresentar situa-se, em certa medida, na continuação de um outro estudo que, há meses, apresentámos no II Congresso Internacional da Associação Portuguesa de Filosofia Fenomenológica, ${ }^{1}$ e cujas conclusões é imprescindível retomar aqui. Um tal estudo procurou abordar o conceito de vida no pensamento de Martin Heidegger, interrogando-se acerca da razão pela qual, depois de admitir, em Sein und Zeit, que a vida é acessível através do Dasein, encontrando-se, portanto, nele, embora não determinando o seu modo de ser, Heidegger separa de forma crescente a vida e o humano até chegar às formulações de Brief über den "Humanismus", ou seja, até chegar à afirmação de que o corpo humano está separado do corpo animal por um abismo e de que o homem, enquanto Da-sein ou "ai" do ser, está mais próximo de um deus que de um ser vivo (Lebewesen). No estudo que propusemos, concluímos que Heidegger recusa de um modo crescente qualquer "contaminação" do Dasein pela vida em função de duas razões principais: por um lado, o contacto intenso com o pensamento de Ernst Jünger, sobretudo a partir da publicação de Der Arbeiter, em 1932; por outro lado, a confrontação com o nacional-socialismo emergente.

A publicação, em 2004, do volume 90 das Gesamtausgabe possibilita documentar até que ponto se estende a relação do pensamento de Heidegger com Jünger, a partir dos anos 30. Para Jünger, a vida é o modo mais completo da mobilização total (totale Mobilmachung), num processo caracterizado pela absoluta determinação do singular pela figura (Gestalt). Se a mobilização total consiste na determinação do singular (Einzelne) já não como indivíduo (Individuum), mas como tipo (Typus), é o animal enquanto ser vivo que paradigmaticamente configura esta determinação. $O$ trabalhador de Jünger é o homem

1 A Vida e o Humano em Heidegger: a ontologia heideggeriana na aurora de uma biopolítica. O texto foi publicado no volume das Actas lo II Congresso Internacional da AFFEN. 
que passa do indivíduo ao tipo; o homem que, diante de um mundo mobilizado por aquilo a que a terminologia de Der Arbeiter chama o "carácter total do trabalho" (totaler Arbeitscharakter), se converte de sujeito em objecto participante da mobilização. Assim, poder-se-ia dizer que o trabalhador jüngeriano, isto é, o homem que se adequa inteiramente à sua figura, despojando-se da sua própria individualidade e conformando a sua singularidade ao tipo que nele é cunhado pela própria figura, consiste, a partir desta caracterização, numa inteira redução da sua essência à própria vida. Noutros termos: a emergência de um tal trabalhador num mundo mobilizado pelo trabalho consistiria naquilo a que se poderia chamar - antecipando a formulação de Kojève - uma "animalização do homem". E é diante desta animalização do homem que, a partir da sua confrontação com Jünger, Heidegger recua. O progressivo afastamento entre o Dasein e a vida enquanto modos de ser, que se torna crescente na obra de Heidegger a partir da década de 30 , pode ser entendido justamente como a manifestação deste recuo.

Para além da confrontação com a obra de Jünger, é a confrontação com o nacional-socialismo que leva Heidegger a esta separação entre Dasein e vida. Com a chegada ao poder do nazismo na Alemanha, em Janeiro de 1933, a vida adquire o estatuto explícito de um objecto do cuidado e do cultivo políticos. $\mathrm{E}$ tal significa uma profunda mudança naquilo a que se poderia chamar a constituição intrínseca do poder, quer no que toca ao seu sujeito, quer no que respeita ao seu objecto. Em primeiro lugar, esta mudança traduz-se na transformação da vida em algo que se encontra inteiramente exposto como objecto de um poder que, diante dela, se exerce imediatamente, sem qualquer resistência nem limitação. Como mostraram os estudos de Michel Foucault ou, mais recentemente, de Roberto Esposito acerca do conceito de "biopolítica", os homens reunidos numa sociedade política tornam-se assim, de um modo inteiramente explícito, num bios cuja saúde deve ser cultivada e promovida. É assim que, para os nacionais-socialistas, a sociedade surge como uma substância étnica homogénea: um corpo orgânico cuja consistência deveria ser preservada através da purga de elementos parasitários e estranhos, assim como de medidas higiénicas e eugénicas. E é assim também que o espaço desta sociedade surge já não propriamente como uma esfera pública, fundado numa limitação normativa e jurídica do exercício do poder, mas como um espaço anómico, como uma "vida nua" - para usar o termo de Giorgio Agamben diante da qual o exercício do arbítrio se normaliza. Em segundo lugar, aquilo a que se poderia chamar a mudança do estatuto da vida, no contexto da biopolítica, implica uma alteração concomitante do próprio poder e da própria política. Esta torna-se então naquilo a que se poderia chamar não tanto uma biologia, mas - para ser mais exacto - uma "zoologia política". E tal quer dizer que ela se determina por ter a "vida nua" como o seu objecto e a sua meta. A determinação do homem por aquilo a que se chamava, na Alemanha dos anos 30, o "sangue e solo", o Blut und Boden, adquire aqui a configuração concreta 
da constituição da vida como pura exposição a um poder biopoliticamente determinado. Dir-se-ia então que, marcada pela sua absoluta exposição ao poder, a vida está agora à disposição de um poder caracterizado, na sua mais íntima essência, como a possibilidade de a determinar, atribuindo-lhe a dignidade de ser vivida ou retirando-lhe essa dignidade. E o poder, por seu lado, na Alemanha nacional-socialista, tem agora a sua suprema manifestação na possibilidade de assinalar uma "vida indigna de ser vivida", marcando-a com a autorização de uma eutanásia piedosa ou de uma "morte misericordiosa" (Gnadentod).

No contexto da Alemanha dos anos 30, o pensamento filosófico não pode deixar de se confrontar sobretudo com este "biologismo". E, neste contexto, a tentativa deliberada de separar por um abismo a vida em relação ao modo de ser do homem tem, de um modo imediato, o significado de uma recusa da biopolítica nacional-socialista. Como vimos, em 1927, ao eleger o termo Dasein para designar o modo de ser do homem, Heidegger não separa dele radicalmente o modo de ser da vida, mas diz apenas que esta mesma vida, estando no Dasein e sendo acessível através dele, não pode constituir um modo de ser genérico para todos os entes viventes, pois admitir a vida como um género corresponderia a reduzir a existência, o Dasein, a uma mera diferença específica. A partir de Sein und Zeit, no entanto, o abismo entre a vida e o Dasein vai-se alargando. E é, curiosamente, com este alargamento que coincide uma semelhante separação entre os termos Dasein e vida (Leben) pela terminologia nacional-socialista, na medida em que tal terminologia atribui à "mera existência", a um reines Dasein, o sentido de uma vida menor e sem valor. Poder-se-ia comparar o uso dos termos Dasein e Leben por Heidegger com o seu uso pelo vocabulário político do nacional-socialismo, cujos resultados vemos traduzidos, por exemplo, no título de um filme feito em 1935 para a instrução do pessoal encarregue de um programa de eutanásia de "existências" com deficiências: Dasein ohne Leben, Existência sem vida. ${ }^{2}$ A comparação levar-nos-ia a uma contraposição interessante. Para os nacionais-socialistas, o homem aparece como essencialmente vida. Tal quer dizer que ele é essencialmente determinável por um cuidado biopolítico, cuja tarefa deve consistir em separar a vida propriamente dita de um mero "Dasein sem vida", da mera existência de uma "vida indigna de ser vivida". Para Heidegger, pelo contrário, o homem é essencialmente existência ou Dasein. E a sua separação crescente em relação à vida indicia a tentativa de Heidegger para encontrar no Dasein uma instância alternativa à determinação biopolítica do homem. É este o sentido das suas críticas ao biologismo, assim como das críticas, formuladas em lições públicas, dirigidas abertamente a autores nacionais-socialistas como Alfred Rosenberg ou Erwin Guido Kolbenheyer, na sua proposta de uma 
compreensão do homem e do seu modo de ser, da linguagem e da poesia, sob a determinação biológica da vida e, particularmente, da raça.

É então sobretudo a confrontação com o biologismo nacional-socialista que explica o tratamento por Heidegger do conceito de vida. Tal tratamento poderia ser resumido do seguinte modo: se, para os nacionais-socialistas, o homem era determinado como vida, e a vida era uma instância essencialmente exposta ao poder biopolítico, o qual se caracterizava por poder distinguir da vida propriamente dita uma mera existência, para Heidegger, pelo contrário, o homem tem de ser, antes de mais, determinado negativamente como não vida; e é ao separar inteiramente, enquanto modos de ser, vida e Dasein que Heidegger determina a essência do homem, antes de mais, pela sua inacessibilidade e recusa ao poder, pela sua opacidade diante da total exposição ao poder da própria vida. Contudo, partindo da interpretação que propomos, se Heidegger tiver em mente, no seu tratamento do conceito de vida, a contestação a uma exposição total do ser do homem a um poder de mobilização, a evocação de um afastamento total da vida em relação ao Dasein não seria suficiente para uma determinação por Heidegger da essência do homem. E a razão desta insuficiência é simples. $\mathrm{O}$ afastamento entre o Dasein e a vida, a recusa de qualquer contaminação do Dasein pela vida, corresponderia apenas a uma caracterização negativa do homem, dizendo aquilo que o homem, na sủa essência, não é. Para uma caracterização positiva, Heidegger teria de voltar a abordar a sua determinação do ente humano como Dasein, mostrando de que forma o ser deste mesmo Dasein, aquilo a que, em 1927, Heidegger tinha chamado o ser-no-mundo, surgia como incompatível com uma redução do homem a uma mera vida exposta ao poder e mobilizada por este. É justamente esta tarefa de revisão que, em larga medida, ocupa Heidegger a partir da publicação de Sein und Zeit.

Em Sein und Zeit, ao determinar o Dasein como ser-no-mundo, Heidegger assinala o ente humano através de uma essencial abertura ao ente. Nesta abertura essencial ao ente, o mundo é, enquanto momento constitutivo da estrutura do ser-no-mundo, a condição de possibilidade da própria abertura. É enquanto condição da abertura do Dasein ao ente que o mundo pode ser determinado, em Sein und Zeit, do seguinte modo: "O mundo não é ele mesmo um ente intra-mundano, e, no entanto, determina de tal modo este ente que este só se pode encontrar, e que só se pode mostrar um ente descoberto no seu ser, na medida em que "há' mundo"3; "O mundo, ainda que não tematicamente, está previamente já descoberto com tudo aquilo que se encontra". ${ }^{4}$ É então enquanto condição do encontro e da descoberta do ente pelo Dasein, enquanto condição da abertura deste mesmo Dasein ao ente, que o mundo aparece considerado em Sein und Zeit. E é neste sentido que ele surge aqui

3 Martin Heidegger, Sein und Zeit, Tübingen, Max Niemeyer, 1996, p. 72.

4 Idem, p. 83. 
também, no ser deste mesmo Dasein, como a condição da verdade. Como escreve Heidegger: "Enquanto o Dasein é essencialmente a sua abertura, e, enquanto aberto, abre e descobre, ele é essencialmente "verdadeiro". O Dasein está 'na verdad'." Este "estar na verdade" próprio do Dasein constitui então o seu ser enquanto ser-no-mundo. E é a partir dele que, em Sein und Zeit, a não-verdade surge para o Dasein como uma possibilidade ôntica. Enquanto constituído por uma essencial abertura ao ente, o Dasein não pode deixar de ser constituído também pela possibilidade fáctica do seu fechamento. Contudo, como Heidegger torna explícito, a não-verdade, sendo co-originária à verdade, só o é a partir desta mesma verdade, do mesmo modo que o fechamento só se torna possível a partir de uma abertura primordial: "Só na medida em que o Dasein é aberto é que ele também é fechado; e é na medida em que, com o Dasein, está já sempre descoberto um ente intra-mundano que semelhante ente, enquanto algo que possivelmente se encontra intra-mundanamente, é escondido (encoberto) ou deslocado". ${ }^{6}$ Para o Heidegger de Sein und Zeit, o Dasein, enquanto ser-no-mundo, é marcado, na sua mais íntima estrutura, pela verdade enquanto não-estar-encoberto (Unverborgenheit), desvelamento (Enthüllung) ou descoberta (Entdeckung). E é justamente esta "verdade" originária do Dasein, esta abertura originária do Dasein enquanto ser-no-mundo, que, a partir de Sein und Zeit, Heidegger irá rever de modo a mostrar como a estrutura ontológica do homem, enquanto Dasein, é incompatível com a sua redução a um ente exposto ao poder de um processo a que, em 1930, Ernst Jünger chamará a "mobilização total".

O primeiro passo nesta revisão da estrutura essencial do Dasein aparece já em 1929, com a publicação de Kant und das Problem der Metaphysik, e pode ser caracterizada pelo processo a que Jean Grondin chamou uma radicalisation philosophique de la finitude. ${ }^{7}$ Se a finitude aparecia, em Sein und Zeit, como uma decorrência da constituição do Dasein enquanto estar-lançado no mundo, dir-se-ia que ela surge agora, na constituição essencial do Dasein, como o seu momento mais originário. É a partir desta originariedade que Heidegger pode aqui proclamar: "Mais originária que o homem é a finitude do Dasein nele". ${ }^{8}$ Com esta aquisição pela finitude do estatuto de momento mais originário na estrutura ontológica do Dasein, Heidegger abre caminho a um segundo passo da sua revisão da estrutura essencial do homem, traduzido numa inversão do seu tratamento da essência da verdade. Se, em 1927, a verdade surgia para Heidegger como a base a partir da qual a não-verdade era possível, em 1930, na sua conferência Vom Wesen der Wahrheit, Heidegger apresentará a não-verdade (Un-wahrheit) como sendo mais originária do que a

\footnotetext{
Idem, p. 221.

Idem, p. 222.

Cf. Jean Grondin, Le tournant dans la pensée de Martin Heidegger, Paris, PUF, 198̣7, p. 81.

Martin Heidegger, Kant und das Problem der Metaphysik, Frankfurt, Vittorio Klostermann, 1998, p. 229.
} 
própria verdade. Uma tal apresentação tem lugar, como é sabido, a partir de uma meditação acerca do " $\alpha$ " privativo da palavra grega para verdade: $a ̉ \lambda \eta \dot{\theta} \in \iota \alpha$. E a ả $\lambda \hat{\theta} \theta \in \iota \alpha$ grega surge aqui, antes de mais, como a indicação de que, na sua essência, o ente só pode aparecer, configurando-se na sua individualidade, a partir do ocultamento do ente no seu todo (Seiendes im Ganzen) e do mundo que o sustenta. Como escreve Heidegger: "O estar-encoberto do ente no seu todo, a não-verdade autêntica, é mais antigo do que qualquer revelação deste ou daquele ente". 9 Segundo o Heidegger de Vom Wesen der Wahrheit, para que o ente possa emergir e vir à luz, o mundo que lhe está subjacente tem de se ocultar. E tal quer dizer que, a partir de 1930, se torna possível a Heidegger dizer que a não-verdade está inserida na própria essência mais originária da verdade. Assim, se a verdade alberga agora em si a não-verdade, se a essência da verdade consiste agora numa originária não-verdade, esta não-verdade encontra-se agora na essência do próprio Dasein enquanto ser-no-mundo. E é esta pertença da não-verdade ao ser-no-mundo que permite a Heidegger escrever, em Vom Wesen der Wahrheit: "O Dasein [...] guarda o primeiro e mais vasto não-desencobrimento, a não-verdade autêntica. A autêntica não-essência da verdade é o mistério". ${ }^{10}$ Torna-se então claro o contributo de Vom Wesen der Wahrheit para esta revisão por Heidegger da essência do homem. Por um lado, a essência da não-verdade consiste no mistério. Por outro lado, a não-verdade originária coincide com a própria essência da verdade na qual o Dasein está enquanto ser-no-mundo. Consequentemente, enquanto ente aberto ao ente no seu todo e lançado no mundo, torna-se possível dizer que o homem é habitado por um mistério irredutível que o distingue essencialmente da pura vida e o torna imune a uma total mobilização. A vida, considerada numa perspectiva biologista, encontra-se exposta à sua mobilização por um poder que se torna, nessa medida, um biopoder. Diante de uma tal mobilização, dir-se-ia que, em contraposição à vida, o homem, constituído na sua estrutura ontológica como ser-no-mundo, é agora essencialmente um mistério sempre irredutível à sua exposição ao poder.

Estes processos de "radicalização filosófica da finitude" e de enraizamento da não-verdade na essência da verdade culminam num terceiro passo da revisão do tratamento dado por Sein und Zeit à constituição do Dasein como ser-no-mundo. Com este terceiro passo, é o próprio mundo, enquanto momento da constituição ontológica do homem, que se torna irredutível à mobilização. Dir-se-ia então que Heidegger tem aqui de pensar a presença no próprio seio do mundo do Dasein enquanto ser-no-mundo daquilo a que, em

9 Martin Heidegger, "Vom Wesen der Wahrheit", in Wegmarken, Frankfurt, Vittorio Klostermann, 1976, pp. 193-194. [Usamos aqui a tradução de Carlos Morujão, embora ligeiramente modificada, a fim de manter a nossa coerência terminológica: Sobre a essência da verdade, Porto, Porto Editora, 1995, p. 47]. 
Vom Wesen der Wahrheit, chama o mistério. E é como uma manifestação do mistério intrínseco ao mundo que este, enquanto condição possibilitante da abertura do Dasein e da manifestação do ente, surge, a partir dos anos 30, intrinsecamente associado à terra e, nessa medida, a uma potência telúrica que, no seu fechamento sobre si mesma, se contrapõe ao carácter pura e simplesmente aberto do próprio mundo. Em 1935, na sua conferência Der Ursprung des Kunstwerkes, Heidegger apresenta então a relação indissociável entre mundo e terra: trata-se de uma relação contenciosa, de uma luta originária, de um Urstreit, na qual cada contendor apenas é ele mesmo a partir da própria contenda e em virtude do adversário que se lhe contrapõe. Como escreve Heidegger: "O confronto de mundo e terra é um combate. [...] A terra não pode prescindir do aberto do mundo, se há-de aparecer como terra no afluxo liberto do seu fechar-se. O mundo, por sua vez, não pode desprender-se da terra, se se há-de fundar, como amplitude vigente e via de todo o destino essencial, sobre algo de decisivo"; "11 "A terra só irrompe pelo mundo, o mundo só se funda na terra na medida em que a verdade acontece como combate originário de clareira e encobrimento". ${ }^{12}$ Assim, se em 1927, com a publicação de Sein und Zeit, o mundo aparecia no pensar heideggeriano apenas como a condição de possibilidade da abertura do Dasein ao ente, torna-se possível dizer que em 1935, através da sua associação intrínseca à terra, este mesmo mundo surge como a condição de que o homem, na sua essência enquanto ser-no-mundo, seja compreendido como fechado sobre si, impenetrável por uma potência mobilizadora e, nessa medida, imune a qualquer poder que procure determinar a sua essência como pura exposição ao poder. Noutros termos: ao trazer a terra para o âmago do mundo, tornando-a naquilo a que se poderia chamar o correlato agónico deste mesmo mundo, Heidegger pode então completar a sua revisão do Dasein enquanto ser-no-mundo, marcando-o por uma opacidade e por uma irredutibilidade que a associação explícita entre o mundo e a terra não pode deixar de indicar.

Poder-se-ia dizer então que Heidegger introduz o mistério no mundo e, nessa medida, no próprio ser do homem através da terra. Contudo, a alusão à terra como condição do mistério do mundo e do homem não pode deixar de conduzi-lo a uma meditação, a uma tentativa de encontrar o sentido (Besinnung) da mobilização total do ente - e em particular da mobilização total da vida pelo biologismo - à luz da relação de luta originária entre mundo e terra, naquilo a que chamará uma confrontação pensante (denkende Auseinandersetzung) com o processo de crescente exposição do ente no seu todo à sua mobilização por um poder mobilizador. Se o mundo se encontra essencialmente associado à terra, se não pode haver abertura do mundo senão como a emer-

11 Martin Heidegger, "Der Ursprung des Kunstwerkes", Holzwege, Frankfurt, Vittorio Klostermann, 1994, p. 35 [Usamos aqui a tradução de Irene Borges-Duarte e Filipa Pedroso: "A origem da obra de arte", Caminhos de Floresta, Lisboa, Gulbenkian, 2002, pp. 47-48]. 
gência (Aufgang) de um mundo a partir da terra, ou seja, como a abertura do fechamento já sempre intrínseco à própria terra, a crescente mobilização total do mundo não poderia acontecer senão como um processo caracterizável como uma retirada da terra em relação ao mundo ou, o que é o mesmo, como uma destruição da terra acompanhada por uma desertificação do próprio mundo. No mesmo ano da conferência que originou Der Ursprung des Kunstwerkes, nas suas lições do Semestre de Verão de 1935, intituladas Einführung in die Metaphysik, Heidegger pode então falar de um processo de declínio (Verfall) no qual, através do desaparecimento da terra e do consequente isolamento do mundo, o homem se torna uma massa mobilizável, e o mistério, representado como uma fuga dos deuses, se retira de todos os entes: "O declínio espiritual da terra progrediu tanto que os povos ameaçam perder a última força espiritual que lhes possibilita apenas ver e avaliar como tal o declínio [visado em referência ao destino do "ser"]. Esta simples verificação nada tem a ver com pessimismo cultural, nem certamente também com um optimismo; pois a desertificação do mundo, a fuga dos deuses, a destruição da terra, a massificação do homem, o desprezo de ódio contra tudo o que é criador e livre já alcançou, em toda a terra, uma medida tal que categorias tão pueris como pessimismo e optimismo já há muito se tornaram ridículas". ${ }^{13}$ A partir da associação entre terra e mundo, Heidegger pode então compreender a história de uma crescente mobilização do ente no seu todo, a história que permite o estabelecimento do homem como pura vida, como um acontecer marcado por uma fuga dos deuses, por um despojamento do mistério e, nesse sentido, por um progressivo abandono do mundo pela terra. E este abandono, longe de traduzir um evento acidental, consiste, para Heidegger, num acontecimento constitutivo do próprio ser do homem enquanto ser-no-mundo. Se o Dasein é, na sua essência, ser-no-mundo, o desaparecimento da terra no mundo é um acontecimento que constitui o ser deste mesmo Dasein. A retirada da terra, o despojamento do mundo de qualquer mistério, coincidente com a sua mobilização total, consiste então num acontecimento que se apropria do homem enquanto Dasein, num Er-eignis que, constituindo o seu próprio ser, lhe assinala a sua história como "história do ser" (Seinsgeschichte).

A fuga dos deuses, o desaparecimento do mistério, a destruição da terra e a desertificação do mundo, com a consequente exposição do ente no seu todo à sua mobilização total, são então compreendidos como configurações possíveis de um processo essencial de Seinsverlassenheit, de abandono do ente pelo ser. Tal quer dizer então que o próprio ente é aqui pensado por Heidegger, a partir do abandono do ser, como um ente despojado de mundo. Do mesmo modo que a terra se retira do mundo, dir-se-ia que é agora o próprio mundo que abandona o ente e o deixa como um puro e simples objecto exposto e mobili-

13 Martin Heidegger, Einführung in die Metaphysik, Gesamtausgabe, vol. 40, Frankfurt, Vittorio Klostermann, 1983, p. 41. 
zado. Por outras palavras: do mesmo modo que a terra é destruída, dir-se-ia que é agora o próprio mundo que chega ao fim, diante da total exposição e mobilização do ente. Contudo, a partir deste abandono do ente pelo ser, a partir daquilo a que se poderia chamar o fim do mundo, Heidegger não poderia deixar de evocar novamente a sua recusa de um despojamento daquilo a que, em 1930, chamara o mistério. Se a preocupação de Heidegger, manifestada sobretudo na sua recusa de considerar o Dasein como vida, consiste em recusar a redução do ente a um mero objecto exposto à mobilização total, o pensar de Heidegger acerca da história do ser, o seu pensar acerca do abandono do ente pelo ser, não pode deixar de assentar naquilo a que se poderia chamar uma recusa do fim do mundo, ou seja, numa meditação (Be-sinnung) em que o abandono do ser possa manifestar o seu sentido não enquanto pura e simples ausência, mas enquanto modo de presença do próprio ser. Dir-se-ia então que, com a sua alusão à fuga dos deuses, à destruição da terra e à desertificação do mundo, Heidegger não pensa o fim deste mesmo mundo e a sua pura e simples mobilização total. Pelo contrário: para Heidegger, a Seinsverlassenheit, o abandono do ente pelo ser é não uma pura e simples ausência do ser, mas um modo de presença deste mesmo ser no ente através da sua ausência. Por outras palavras: se uma pura e simples mobilização total do ente consistiria no desaparecimento da terra no mundo, ou no fim do mundo no ente, pode-se dizer que, no seu pensar da história do ser, Heidegger se detém justamente no fim do mundo. Os Beiträge zur Philosophie, escritos entre 1936 e 1938, são aqui o melhor exemplo deste recuo de Heidegger diante do fim do mundo. Aqui, o ser não é (ist), mas é essencialmente, essencia-se num ente (west). Assim, a total exposição do ente à sua mobilização, o abandono do ente pelo ser, consiste não num desaparecimento por parte do ser, mas num modo de ser deste mesmo ser, essenciando-se como essência do próprio ente que acontece. Noutros termos: o abandono do ser é, como diz Heidegger nos Beiträge zur Philosophie, "no fundo, uma des-essenciação [Ver-wesung]"; mas, por seu lado, esta é um modo essencial da sua essenciação (Wesung). Daí que, nos Beiträge, Heidegger possa caracterizar o abandono do ser não como uma pura e simples ausência do ser, não como o puro e simples fim do mundo, mas como o modo de essenciar-se do ser pelo qual ele aparece segundo a aparência do fim do mundo, essenciando-se como se (als ob) ele já não se essenciasse no ente. Como escreve Heidegger: "O ente aparece então assim, aparece como objecto e como algo aí-diante, como se o Ser não se essenciasse". ${ }^{14}$

A recusa de Heidegger de compreender o abandono do ser, e a mobilização total que desta decorre, como o fim do mundo, ou seja, a sua recusa de compreender o abandono do ser como um puro e simples despojamento de ser do próprio ente, e como uma redução do homem a vida exposta a um poder

14 Martin Heidegger, Beiräge zur Philosophie (Vom Ereignis), Frankfurt, Vittorio Klostermann, 1989, p. 115. 
biopolítico, torna-se manifesta sobretudo no ano de 1953, ano em que, para além de publicar as suas lições de 1935, Einführung in die Metaphysik, num volume separado, Heidegger pronuncia a sua conferência Die Frage nach der Technik. Assim, se, naquelas, Heidegger podia voltar a falar num declínio baseado numa massificação do homem, numa destruição da terra e numa desertificação do mundo, Heidegger apresenta agora, nesta conferência, a essência da técnica moderna não como um fim do mundo, ou como um completo despojamento do ente, mas como a possibilidade de um "outro início" da sua história. Nesta conferência, como se sabe, a essência da técnica moderna aparece como uma com-posição (Ge-stell) caracterizada não apenas por um produzir do ente, mas por um pôr desse mesmo ente como um Bestand, como algo reservado, armazenado, encomendado e desafiado. Na técnica moderna, o ente é e desencobre-se não simplesmente como algo que aparece, mas como algo de que se extrai, se armazena e se expõe tudo aquilo que nele estava encoberto. E a um tal desencobrir-se do ente chama Heidegger agora desafio (Heraus-forderung). Contudo, se o ente é agora não simplesmente algo posto aí-diante, mas algo posto como desafiado, se este ente está agora inteiramente exposto a um poder que se exerce sobre ele, tal não quer dizer, para Heidegger, que esta exposição ou mobilização total do ente se traduza no puro e simples fim daquilo a que em 1930 chamara o mistério do ente. O ponto principal da abordagem por Heidegger da essência da técnica consiste na apresentação do desafio não como o fim do encobrimento no qual o ente surge como desencoberto, mas como um modo de desencobrimento do ente a partir da permanência do encobrimento enquanto condição do próprio desencobrimento. Daí que Heidegger possa escrever: "O desencobrir que predomina na técnica moderna tem o carácter do pôr no sentido do desafio. Este acontece na medida em que as energias encobertas na natureza são abertas, aquilo que é aberto transformado, aquilo que é transformado armazenado, aquilo que é armazenado novamente dividido, e aquilo que é dividido, de novo, reconfigurado. $\mathrm{O}$ abrir, transformar, armazenar, dividir, reconfigurar são modos do desencobrir. Este simplesmente não termina". ${ }^{15}$ É através desta persistência do desencobrir do ente no próprio desafio, ou seja, é a partir da persistência do ser, no seu encobrimento originário, no próprio desencobrimento desafiante do ente, que Heidegger pode fazer aqui sua a máxima de Hölderlin: "onde está o perigo, cresce também o que salva". E é justamente esta persistência, no próprio perigo, daquilo que salva que mostra que o pensar de Heidegger em torno da essência da técnica moderna consiste não num pensar do fim do mundo, mas num pensar de um "outro início" (der andere Anfang) da sua história. Daí que Heidegger conclua da sua meditação sobre a técnica: "O domínio da com-posição ameaça com a sua possibilidade de que ao homem possa ser recusado

${ }^{15}$ Martin Heidegger, "Die Frage nach der Technik", Vorträge und Aufsätze, Estugarda, Neske, 2000, p. 20. 
inflectir para um descobrir mais originário e, assim, experimentar a solicitação de uma verdade mais inicial. Assim, onde a com-posição domina, está o perigo no mais elevado sentido. 'Mas onde está o perigo, cresce também o que salva'."

A possibilidade do salto para um outro início acompanha todo o pensar de Heidegger acerca do abandono do ser. Dir-se-ia que o pensar de Heidegger se determina essencialmente por se deter diante da possibilidade de que a mobilização total do ente coincida com o esgotar do mistério do ente, com o fim do mundo desse mesmo ente. E é esta posição fundamental de Heidegger que dá ao seu pensar o carácter fundamental de uma meditação, de uma $B e-$ -sinnung, de uma tentativa de encontrar o sentido (Sinn) do próprio abandono do ser à luz de uma história do ser e de um acontecer do ser no ente como Ereignis, ou seja, como instância que, acontecendo no ente, o apropria e lhe propicia um sentido. Ao deter-se diante do fim do mundo, tornando-se assim meditação, o pensar de Heidegger é essencialmente marcado pela abertura a um "vindouro", a um Zu-künftiges, que surge, diante da história do abandono do ser que constitui a história do primeiro início deste mesmo ser, como um "outro início". Um tal "outro início" surge assim, para Heidegger, não como um movimento contrário ao "primeiro início", nem como um segundo início na sequência do primeiro. Como escreve Heidegger: "Não é nenhum contra-movimento; pois todos os contra-movimentos e contra-forças são co-determinados, na sua parte essencial, pelo seu contra, mesmo que na figura de uma sua inversão. E daí que um contra-movimento nunca baste para uma transformação essencial da história [...] O outro início não é a contra-orientação em relação ao primeiro, mas está, enquanto outro, fora do contra e da comparabilidade imediata". ${ }^{17}$ E se o outro início é, em relação ao primeiro, algo inteiramente outro, tal quer dizer que a alusão ao outro início significa não uma determinação deste outro início, nem sequer uma determinação do que se passa na passagem do primeiro para o outro início, mas a determinação de que a referência a este outro início, inteiramente indeterminado, vigore como a referência essencial de um pensar que se constitui como meditação, ou seja, como uma tentativa de desencobrir o sentido encoberto da história do próprio ser no seu abandono do ente. É então como a referência a um outro início vindouro, o qual permanece sempre quer inteiramente indeterminado, quer inamovível do horizonte do pensar, que o pensar de Heidegger, enquanto meditação, cumpre a sua tarefa essencial. Daí que Heidegger possa escrever: "A passagem para o outro início está decidida e, no entanto, não sabemos para onde vamos, quando se tornará no que é verdadeiro a verdade do Ser e a partir de onde é que a história, enquanto história do ser, tomará o seu caminho mais íngreme e mais curto". 18

16 Idem, p. 32.

17 Martin Heidegger, Beiträge zur Philosophie (Vom Ereignis), pp. 186-187.

18 Idem, p. 177. 
A meditação de Heidegger acerca da história do ser consiste assim numa tentativa de pensar a mobilização total do ente, levada a um extremo na tentativa de compreender o homem como vida exposta a um poder biopolítico, a partir da recusa de que esta mobilização consista no fim do mundo. Partindo desta recusa como posição fundamental, o pensar meditativo de Heidegger tem lugar como um salto para o vindouro e, neste sentido, como pura e simples remissão ao futuro, tornando-se assim naquilo que Heribert Boeder caracteriza como uma "razão apocalíptica"19 ou uma "razão temporal". ${ }^{20}$ É como uma manifestação deste salto para o vindouro, na sua completa indeterminação, que é possível interpretar a resposta dada por Heidegger em Brief über den »Humanismus" à pergunta "o que é o ser?", por ele mesmo formulada: "Mas o ser - que é o ser? Ele "é" ele mesmo. Experimentá-lo e dizê-lo é o que tem de aprender o pensar futuro". ${ }^{21}$ Diante desta remissão do experimentar e do dizer do ser para um futuro adveniente ou, o que é o mesmo, para um "outro início" da sua história, Heidegger pode então permanecer no âmbito daquilo a que Boeder chama a modernidade, ou seja, no âmbito de um pensar que se determina como uma meditação em torno de uma "coisa" (Sache) do pensar que, perante a mobilização total do ente, se lhe encontra subjacente como um mistério irredutível. Mas se Heidegger, remetendo apocalipticamente para o vindouro, recua diante daquilo a que se poderia chamar o total despojamento do ente, e diante da redução do homem a pura vida biopoliticamente determinada, poder-se-ia ver também no desaparecimento deste vindouro, na transição daquilo a que Boeder chama a modernidade para uma submodernidade, a emergência do fim do mundo frente ao qual a meditação de Heidegger recua. E, aqui, é justamente a construção logotectónica de Boeder, na sua tematização da passagem de uma meditação moderna para uma reflexão submoderna, que permite pensar este fim do mundo. Visto a partir de fora quer do messianismo apocalíptico moderno, quer da "messianidade sem messianismo" submoderna, o fim do mundo emerge então não como um advento apocalíptico, mas precisamente como o fim da sua possibilidade.

19 Cf. Heribert Boeder, "Logotektonisch Denken”, in Sapientia, LIII, Buenos Aires, 1998, p. 19 [trad. port.: „Pensar logotectonicamente“, trad. Alexandre Franco de Sá, Revista Filosófica de Coimbra, $\mathrm{n}^{\circ}$ 26, 2004, p. 444].

${ }^{20}$ Cf. Heribert Boeder, "Die Grenze der Moderne und Heideggers Vermächtnis", Braunschweigische Wissenschaftliche Gesellschaft, Jahrbuch 1990, Göttigen, 1991, p. 81.

${ }^{21}$ Martin Heidegger, "Brief über den »Humanismus«", Wegmarken, p. 331. 


\begin{abstract}
A comunicação situa-se na continuação do estudo apresentado ao II Congresso Internacional da AFFEN, intitulado A vida e o humano em Heidegger: a ontologia heideggeriana na aurora de uma biopolitica, e pretende considerar as consequência, na filosofia de Heidegger na transição entre os anos 20 e 30, do seu afastamento em relação ao conceito de vida. Ver-se-á como é este afastamento, determinado pela meditação em torno do pensamento de Ernst Jünger e pela confrontação com o biologismo nacional-socialista, que conduz àquilo a que se poderia chamar uma transformação interior da abordagem heideggeriana da essência do humano, e da sua determinação como ser-no-mundo. Uma tal transformação acontece em três passos fundamentais: 1. uma "radicalização filosófica" - para usar os termos de Jean Grondin - do conceito de finitude (1929); 2 . um enraizamento da não-verdade na própria essência da verdade (1930); 3. a transformação do conceito de mundo em pólo da unidade constituída pela relação agónica entre terra e mundo (1935). Através desta transformação, Heidegger confronta-se com a meditação jüngeriana acerca da "mobilização total" do mundo, surgindo assim a sua história do ser como a representação de um processo no qual o ser abandona o ente, a terra é destruída e o mundo é despojado de terra. Numa tal história, marcada, numa perspectiva geral, por aquilo a que Heidegger chama a "fuga dos deuses", dir-se-ia que tudo no ente fica exposto e que o mundo - sendo aquilo que, no aparecer do ente, não aparece e se encobre enquanto condição do próprio aparecimento - chega ao fim. Heidegger apresenta então o fim do mundo, através do seu pensar de uma história do ser, para o recusar e resistir contra ele. O salto da "história do ser" para um "outro início" da história, aquilo a que Heribert Boeder chama o "pensar apocalíptico" constitutivo da meditação moderna heideggeriana, traduz assim um recuo de Heidegger diante do fim do mundo.
\end{abstract}


